(5) A quantitative fit of the experimental test results to the dislocation model gives values of $3-4$ for the ratios of total dislocation density to the recoverable component and values of 7-8 dyn $/ \mathrm{cm}^{2}$ for the restoring force constant for the recoverable dislocations. The restoring force constants and recoverable dislocation densities were, within experimental error, found to be independent of temperature, measurement stress and strain-rate, and predeformation level. Values found for the parameters for creep and mechanical after-effect tests were equal within experimental error to the values found from constant strain-rate and stress-relaxation tests carried out on the same sample. If the recoverable dislocation component is identified as bowed-out dislocation segments whose ends are fixed, the restoring force could be accounted for by the elastic line tension of dislocation segments of lengths of about $8 \times \mathrm{IO}^{-3} \mathrm{~cm}$.

No feature of the experimental results was inconsistent with this dislocation model, and the results of the study are all in agreement with the theory proposed by Weertman in which the dislocation drag force is very large because of the stress-induced ordering of water molecules in the stress field of the moving dislocation.

This paper is to be submitted for publication in full in another journal.

\title{
DISGUSSION
}

N. K. Sinha: During the tests I found it difficult to maintain the imposed strain-rate to a constant level. It was also observed that it was impossible to maintain the imposed strain to a constant level in a stress-relaxation test. These are because of the inherent elasticity of ordinary testing machines. Were the experiments on stress relaxation and strain-rate tests performed with a closed-loop testing machine? If not, the experimental results may represent only the response of the ice-machine system.

J. Holder: The tests were carried out in an MTS testing machine, in a closed loop configuration. All strains were monitored by capacitor plates attached direct to the specimen (as opposed to the cross-head).

J. Perez: You have used the Orowan relation; did you take into consideration, at least at higher temperatures, dynamic recovery phenomena leading to values of $\Lambda$ depending on stress and on temperature in the steady state?

Holder: No systematic study of dislocation density as a function of predeformation stress was carried out; our concern was to maintain a constant density during the measurements after the predeformation. Our control in this regard was to compare strain-rates during the actual tests to the strain-rates measured during the predeformation. The densities determined by the equation were the same, within our uncertainty.

\section{EFFECT OF HYDROSTATIC PRESSURE ON THE CREEP OF ICE}

\author{
By Stephen J. Jones
}

(Glaciology Division, Inland Waters Directorate, Department of Fisheries and Environment, Ottawa, Ontario $\mathrm{K}_{\mathrm{I}} \mathrm{A}$ oE 7 , Canada)

Abstract. Uniaxial compressive creep tests on single crystals and polycrystals of ice at about $-\mathrm{IO}^{\circ} \mathrm{C}$ under different hydrostatic pressures are described. After creeping under a constant load at atmospheric pressure for some hours, a hydrostatic pressure of the order of $35 \mathrm{MN} \mathrm{m}^{-2}$ was applied and the change in strain-rate was noted. Some hours later the 
hydrostatic pressure was removed and the test continued at atmospheric pressure. From these changes in strain-rate $\dot{\epsilon}$, an activation volume $V$ was determined from the equation

$$
V=-R T\left(\frac{\partial \ln \dot{\epsilon}}{\partial P}\right)_{\sigma, \tau},
$$

where $R$ is the gas constant, $\mathcal{T}$ is the absolute temperature, $P$ is the hydrostatic pressure and $\tau$ is the superimposed uniaxial creep stress. $V$ is negative if $\dot{\epsilon}$ increases with $P$.

For single crystals, which show an accelerating creep curve, that is the strain-rate increases continuously with time, no sensible activation volume was determined because the strain-rate increased both on the application of the hydrostatic pressure, and on its removal. For polycrystals, application of a hydrostatic pressure caused an increase in strain-rate which gave an activation volume of about $-10 \mathrm{~cm}^{3} \mathrm{~mol}^{-1}$. However, on removal of the pressure the strainrate did not return to its original atmospheric-pressure value implying that steady-state creep had not been reached.

This value of activation volume is in general agreement with two previously published values for creep deformation, but is of opposite sign to the activation volume for dielectric relaxation. Further tests are in progress.

\section{DISCUSSION}

D. TABOR: In calculating the activation volume does the author take into account the fact that hydrostatic pressure raises the melting temperature, i.e. does he use the homologous temperature rather than the absolute temperature? Secondly, ice crystals have markedly anisotropic deformation properties. Consequently polycrystalline specimens subjected to a hydrostatic pressure will experience shear stresses. Could these play a part in the creep behaviour of the polycrystalline material?

S. J. Jones: I hope, of course, to obtain activation volumes both close to the melting point, as shown here, and some considerable distance from it. This will tell us what is the effect of approaching the pressure-melting point. Experimentally, one has to be careful not to exceed the pressure-melting point. In the dielectric experiments one has a similar problem.

J. W. GLEN: In your table you include results for high-pressure phases of ice. Since these, where they have a phase boundary with the liquid, do not contract on melting, the argument about vacancies having a negative effect on volume is not applicable to them.

You did not attempt to deduce an activation volume from your single-crystal data for obvious reasons - but if you had you would have got one positive and one negative value for activation volume. I was very impressed by the consistent results on dislocation movement of pre-stressed ice single crystals presented in this symposium by Joncich and others (1978). It might be a good idea to use such pre-stressed crystals under relatively low stress to determine an activation volume.

W. F. BudD: Regarding the decrease of strain-rate with time which you observe at I bar, we find from long-term creep tests, designed to reach tertiary creep, that the time required to reach a minimum strain-rate greatly increases with decreasing stress. At I bar compression at $-10^{\circ} \mathrm{C}$ we expect that at least several thousand hours would be required to reach a minimum.

Jones: We have started experiments at high stresses to avoid this problem.

\section{REFERENCE}

Joncich, D. M., and others. 1978. Plastic behavior of predeformed ice crystals, by D. M. Joncich, J. Holder and A. V. Granato. Journal of Glaciology, Vol. 21, No. 85, p. 700-0 I. 